\title{
Multi-scale and multi-site resampling of a study area in spatial genetics: implications for flying insect species
}

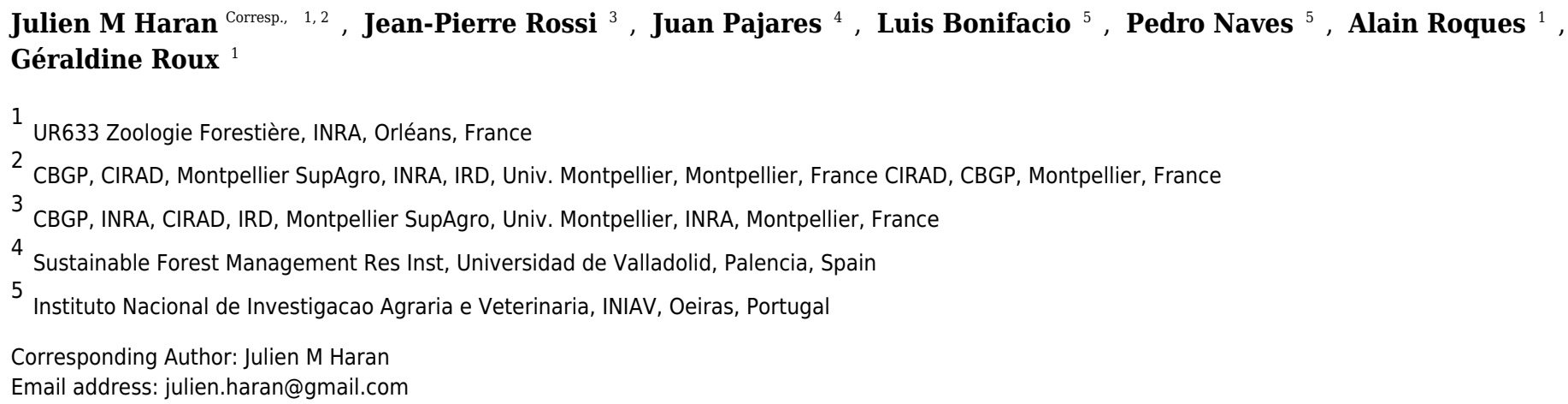

The use of multiple sampling areas in landscape genetic analysis has been recognized as a useful way of generalizing the patterns of environmental effects on organism gene flow. It reduces the variability in inference which can be substantially affected by the scale of the study area and its geographic location. However, empirical landscape genetic studies rarely consider multiple sampling areas due to the sampling effort required. In this study, we explored the effects of environmental features on the gene flow of a flying long-horned beetle (Monochamus galloprovincialis) using a landscape genetics approach. To account for the unknown scale of gene flow and the multiple local confounding effects of evolutionary history and landscape changes on inference, we developed a way of resampling study areas on multiple scales and in multiple locations (sliding windows) in a single large-scale sampling design. Landscape analyses were conducted in $3 * 10^{4}$ study areas ranging in scale from 220 to $1000 \mathrm{~km}$ and spread over 132 locations in the Iberian Peninsula. The resampling approach made it possible to identify the features affecting the gene flow of this species but also showed high variability in inference among the scales and the locations tested, independent of the variation in environmental features. This method provides an opportunity to explore the effects of environmental features on organism gene flow on the whole and reach conclusions about general landscape effects on their dispersal, while limiting the sampling effort to a reasonable level. 


\section{Multi-scale and multi-site resampling of a study area in spatial 2 genetics: implications for flying insect species}

3 JULIEN HARAN ${ }^{1,2,7}$, JEAN-PIERRE ROSSI ${ }^{3}$, JUAN A. PAJARES ${ }^{4}$, LUIS BONIFACIO ${ }^{5}$,

4 PEDRO NAVES ${ }^{5}$, ALAIN ROQUES ${ }^{1}$ and GÉRALDINE ROUX ${ }^{1,2}$

$5 \quad{ }^{1}$ INRA, UR633 Zoologie Forestière, F-45075 Orléans, France.

$6 \quad{ }^{2}$ Université d'Orléans, rue de Chartres, Orléans cedex, France.

$7 \quad{ }^{3}$ CBGP, INRA, CIRAD, IRD, Montpellier SupAgro, Univ. Montpellier, Montpellier, France.

$8{ }^{4}$ Univ Valladolid INIA Palencia, Sustainable Forest Management Res Inst, Palencia, Spain.

95 Instituto Nacional de Investigacao Agraria e Veterinaria - INIAV Oeiras, Portugal.

$10{ }^{7}$ Present address: CBGP, CIRAD, Montpellier SupAgro, INRA, IRD, Univ. Montpellier,

11 Montpellier, France CIRAD, CBGP, Montpellier, France

Corresponding author: Julien HARAN (CBGP, CIRAD, Montpellier SupAgro, INRA, IRD,

Univ. Montpellier, Montpellier, France CIRAD, CBGP, Montpellier, France. Tél.: +33 4996233

04,julien.haran@cirad.fr) 
Abstract

34

The use of multiple sampling areas in landscape genetic analysis has been recognized as a useful way of generalizing the patterns of environmental effects on organism gene flows. It reduces the variability in inference which can be substantially affected by the scale of the study area and its geographic location. However, empirical landscape genetic studies rarely consider multiple sampling areas due to the sampling effort required. In this study, we explored the effects of environmental features on the gene flow of a flying long-horned beetle (Monochamus galloprovincialis) using a landscape genetics approach. To account for the unknown scale of gene flow and the multiple local confounding effects of evolutionary history and landscape changes on inference, we developed a way of resampling study areas on multiple scales and in multiple locations (sliding windows) in a single large-scale sampling design. Landscape analyses were conducted in $3 * 10^{4}$ study areas ranging in scale from 220 to $1000 \mathrm{~km}$ and spread over 132 locations in the Iberian Peninsula. The resampling approach made it possible to identify the features affecting the gene flow of this species but also showed high variability in inference among the scales and the locations tested, independent of the variation in environmental features. This method provides an opportunity to explore the effects of environmental features on organism gene flows on the whole and reach conclusions about general landscape effects on their dispersal, while limiting the sampling effort to a reasonable level. 


\section{Introduction}

60

61

62

Landscape genetics examines the relationship between landscape and environmental features and genetic structure (Manel et al., 2003; Manel \& Holderegger 2013). It enables inference about which environmental features facilitate or hinder gene flow (Zeller et al., 2012), which is a key factor for understanding the persistence and evolution of species and populations and has significant consequences for conservation planning (Castillo et al., 2014; Van Strien et al., 2014). As an emerging and fast moving field, substantial effort to optimize the method is still required in order to make relevant and optimum inferences (Anderson et al., 2010; Cushman et al., 2013; Manel \& Holderegger 2013). Landscape genetic analyses are usually conducted on a single scale and in a single location (Zeller et al., 2012) and therefore provide results that are, strictly speaking, only applicable to the particular area under study (Shortbull et al. 2011). In fact, genetic structure is determined by multiple micro- and macro-evolutionary processes acting on different spatial and temporal scales, and is rarely homogeneously distributed across a study species' distribution range (Waters et al., 2013). For example, in addition to contemporary or historical environmental effects on dispersal (Zellmer \& Knowles 2009), the genetic structure of organisms is often influenced by historic differentiation due to quaternary climate oscillations (Hewitt 2000), or by biased dispersal due to local adaptation to specific environmental conditions (Sexton et al., 2014; Pflüger \& Balkenhol 2014). The diverse factors acting on different temporal and spatial scales may generate genetic patterns that are inconsistent across locations or regions, which results in conflicting signals of environmental factors acting on gene flow. In addition to these multiple limitations, the landscape genetics approach is increasingly being applied to flying organisms with dispersal abilities that are difficult to predict and for which barriers to dispersal may be hard to conceptualize (Zeller et al. 2012). In these situations, an experimental design is difficult to set up a priori, which can lead to limited inference (Dreier et al. 2014).

To integrate these factors and deal with the variability of the results in landscape genetic analysis, several authors have highlighted the importance of two aspects: matching the study 
85

86

87

design to the process being investigated (scale of sampling area, Cushman \& Landguth 2010; Manel \& Holderegger 2013) and considering landscape level replications (multiple locations of sampling areas, Short Bull et al., 2011). The study scale is fundamental in landscape genetics, because species respond to environmental features on a continual range of scales, which may affect correlation coefficients (Anderson et al., 2010; Manel \& Holderegger 2013). This point has been highlighted in several empirical studies and simulation exercises (Cushman \& Landguth 2010; Angelone et al., 2011; Galpern et al., 2012; Dudaniec et al., 2013; Keller et al., 2013), in particular for organisms exhibiting wide home-ranges, such as large mammals (Galpern et al., 2012; Zeller et al., 2014). The scale of the study design is also crucial for flying species for which the scale of gene flow may be much larger than expected (Dreier et al. 2014). However, landscape genetic studies still rarely consider this aspect (Zeller et al., 2012) and how it affects inference in the detection of general effects of environmental features on dispersal and gene flow. Landscape-level replication is another fundamental aspect in landscape genetics (Holderegger \& Wagner 2008). The term replication usually refers to the replication of sampling areas (sampling units; Short Bull et al., 2011). Such an experimental design provides a "quantitative" dimension in landscape genetic analysis, allowing conclusions to be drawn about the general effects of landscape features on the dispersal of organisms. These replications are particularly useful to account for multiple local confounding effects of the genetic structure of organisms detailed above. Few studies have included replication in landscape genetic studies, and the number of replications considered is often small (Driezen et al., 2007; Kindall \& Van Manen 2007; Zalewski et al., 2009; Short Bull et al., 2011).

In order to provide a more complete and comprehensive picture of the general effects of the landscape on the dispersal of organisms, there is a need to integrate various scale and landscape level replications of sampling areas in more empirical landscape genetic studies. However, such exploration often remains limited due to the substantial sampling efforts required. Resampling methods (Sjöstedt-de Lunas 2001) are an interesting perspective in landscape genetics, as they offer the possibility of examining variation of inference in several sub-parts of a single sampling design, potentially including variations of scale and location of study areas. In our study, we developed a method combining multi-site and a multi-scale resampling of sliding windows (study areas) to explore on which scale and in which locations environmental features fostered or hindered the gene flow of a flying insect species: Monochamus galloprovincialis (Coleoptera, 
116 Cerambycidae). We first characterized the broad-scale genetic structure of the beetle across the study area, and we used the "isolation-by-resistance" (IBR) framework to model beetle dispersal as a function of three relevant landscape features (temperature, elevation, and pine cover), called IBR hypothesis (IBR-T, IBR-E and IBR-P respectively). For each of these IBR hypothesis, we then carried out a landscape genetic analysis based in 30576 resampled areas of extents ranging from 220 to $1000 \mathrm{~km}$ and distributed in 132 sampling locations in the Iberian Peninsula. Lastly, we searched for the main landscape features affecting gene flow in M. galloprovincialis and we analyzed how the scale and location of the study area impacted inference.

\section{Methods:}

\section{Sampling and genotyping}

The study area covered the entire Iberian Peninsula $\left(582000 \mathrm{~km}^{2}\right)$ with altitudes ranging from sea level up to $2444 \mathrm{~m}$. M. galloprovincialis specimens were trapped between 2011 and 2013 at 137 sites spread over the Iberian Peninsula. We used multifunnel traps baited with a volatile attractant (Galloprotect, SEDQ, Spain) installed during the summer to catch flying adults. The traps used had a radius of attraction of $100 \mathrm{~m}$ (Jactel et al., 2015) and were placed in dense pine stands (where beetle density is high; Jactel et al., 2015) to limit consanguinity among the individuals caught. After collecting, adults were stored in $96.66 \%$ ethanol at $4^{\circ} \mathrm{C}$. Despite intensive trapping, M. galloprovincialis was not recorded in the central lowlands of Castilla y Leon, central Galicia and Asturias districts (Fig. S1). We obtained 1050 individuals at 132 sites, with an average sample per location of 7.68 individuals. Therefore, sampling consisted of a trade-off between the number of localities and the size of demes, keeping the sampling effort at a realistic level. Details of sampling localities and year of collection are given in table S1. Individuals collected at the same locality were considered as one deme. The distribution of sites covered most of the pines forests found in the Iberian Peninsula (Fig. S1).

DNA was isolated from two legs per individual using a Nucleospin Kit (Macherey-Nagel, Düren, Germany). Specimens were genotyped at 12 microsatellite loci (Mon01, Mon08, Mon17, Mon23, Mon27, Mon30, Mon31, Mon35, Mon36, Mon41, Mon42 and Mon44; Haran \& Roux- 
144 Morabito 2014). Details of primer sequences and the protocol for genotyping are given in Table 145 S2. Results showing negative or ambiguous amplification of particular loci were repeated once 146 and considered null when still unsatisfactory. Individuals exceeding two missing loci were 147 removed for the analysis. Deviation from Hardy Weinberg Equilibrium $\left(F_{i s}\right)$ was estimated for 148 each deme, each inferred cluster and for the whole dataset using GENEPOP 4.2 (Raymon \& 149 Rousset 1995). The frequency of null alleles at each locus was tested using FREENA (Chapuis \& 150 Estoup 2007) among three large demes $(n>19)$. Loci exceeding a rate of $7 \%$ of null alleles across 151 populations were discarded from further analysis. Allelic richness was computed for each deme using rarefaction (HP-RARE, Kalinowski 2005). The absence of linkage disequilibrium between pairs of loci was reported in a previous population-based study (Haran et al., 2015).

\section{Genetic structure}

156

157 158

159

160

161

162

163

164

165

166

167

168

169

170

171

172

We used the Bayesian approach implemented in STRUCTURE 2.3.4 (Pritchard et al., 2000) to identify the main genetic clusters among Iberian demes. STRUCTURE assigns individuals to a predefined number of clusters based on allele composition and linkage disequilibrium. We used the Delta K method (Evanno et al., 2005) to determine the number of clusters $(\mathrm{K})$ that best fitted the data. Genotypes were analyzed using default parameters (admixture model, correlated allele frequency). We made ten repeats of a 200,000 burn-in period followed by 500,000 replicates of Markov Chain Monte Carlo (MCMC), for K values ranging from 1 to 20. The results were uploaded in STRUCTURE HARVESTER (Earl et al., 2012) to determine the optimum K. We also explored the existence of genetic clusters among demes using a principal component analysis (PCA) performed on allele frequencies (Adegenet package, Jombart 2008). To account for potential confounding effects of differentiated genetic clusters (possibly of evolutionary history origin) on the inference of gene flow, the landscape genetic analyses of this study (see below) were performed twice, once within the main cluster identified by STRUCTURE and PCA, and once with the whole dataset including all clusters.

The genotypes of $M$. galloprovincialis were also analyzed taking a spatial approach in order to identify nested levels of genetic structure linked to scales of study. The scores of the sampling locations on axis 1 of the PCA are linear descriptors of the allele frequencies and, as such, can be 
173 used as a univariate statistical measure of genetic composition. The scores may encapsulate 174 relevant spatial information, so we explored this point using a specific tool borrowed from 175 geostatistics: the variogram (Wagner et al., 2005, Goovaerts, 1997). The variogram is used in all 176 branches of life sciences in order to explore spatial patterns and determine the main spatial scales 177 on which structures occur. In our study, we analyzed the score of sample points on axis 1 using a 178 variogram to gain a better understanding of the spatial component of the variation encapsulated in 179 the first axis of the PCA. Let $\mathrm{z}\left(\mathrm{u}_{\alpha}\right)$, with $\alpha=1,2, \ldots \mathrm{n}$, be a set of $\mathrm{n}$ values of sample scores on a 180 PCA axis where $\mathrm{u}_{\alpha}$ is the vector of spatial coordinates of the $\alpha$ th observation. In geostatistics, 181 spatial dependence is described in terms of dissimilarity between observations expressed as a

182

183

184

185

186

187

188

189

190

191

192

193

194

195

196

197

198

199

200 function of the separating distance (Goovaerts 1997). The average dissimilarity between data separated by a vector $h$ is measured by the empirical semi-variance $\hat{y}(h)$, which is computed as half of the average squared difference between the data pairs:

$$
\hat{\gamma}(h)=\frac{1}{2 N(h)} \sum_{x=1}^{N(h)}\left[z\left(u_{\alpha}\right)-z\left(u_{\alpha}+h\right)\right]^{2}
$$

where $N(h)$ is the number of data pairs for a given lag vector $h, z\left(u_{\alpha}\right)$ and $z\left(u_{\alpha}+h\right)$ the score values of all sample locations separated by a vector $h$. The more alike the observations at points separated by $\mathrm{h}$ are, the smaller $\hat{y}(\mathrm{~h})$ will be, and vice versa. The plot of $\hat{y}(\mathrm{~h})$ against $\mathrm{h}$ is called a variogram and represents the average rate of change of $z$ with distance. Its shape describes the pattern of spatial variation in terms of general form, scales and magnitude (Goovaerts 1997).

Variograms are good tools for depicting spatial structures and analyzing nested patterns (Burrough 1983); when structures occur on different spatial scales, the resulting variogram exhibits different plateaus (horizontal flattening of the curve) in association with different scales (Robertson and Gross 1994; Rossi 2003). The range of the variogram is the distance at which the plateau occurs. Multi-plateau variograms exhibit different ranges which provide synthetic information about the spatial scales in play. Readers are referred to Goovaerts (1997) for a thorough introduction to variograms and geostatistics and to Wagner et al., (2005) and to Guillot et al. (2009) for an introduction to this tool in the field of population genetics. Variograms were computed using the R geoR package (Ribeiro and Diggle 2001). 
202

203

204

205

206

207

208

209

210

211

212

213

214

215

216

217

218

219

220

221

222

223

224

225

226

227

228

229

\section{Landscape genetic analysis}

Conventional landscape genetic analyses were first carried out by computing pairwise genetic distances and landscape resistance distances, and then by correlating them.

Computing pairwise genetic distances. Genetic distances were computed between pairs of individuals using an individual-based metric (Shirk et al., 2010; Prunier et al., 2013). We first constructed a matrix where each individual was a row and alleles were columns and where genotypes were coded for each allele as 0 when absent, 1 when single at a locus (heterozygotes) or 2 for homozygotes (Shirk et al., 2010). Thus, individuals were represented as a linear vector of size $\mathrm{n}$, where $\mathrm{n}$ was the total number of alleles encountered in all the individuals genotyped. We then generated a semi matrix of distance between all pairs of individuals. We computed the BrayCurtis percentage of dissimilarity (Legendre \& Legendre 1998) to estimate differentiation between all pairs of individuals. Calculations were performed using the $\mathrm{R}$ vegan package (Oksanen et al., 2016).

Computing landscape resistance distances. We then selected the environmental features considered to be the most likely to influence the dispersal of $M$. galloprovincialis given the existing knowledge of species requirements. Apart from Euclidian geographic distances (null model), we considered three environmental features to be potential drivers of dispersal (pine density, temperature, and elevation).

Environmental resistance to dispersal was modeled as a function of pine density as this parameter determines the volume of resource available for $M$. galloprovincialis and is thought to affect its foraging dispersal. As the dispersal behavior of this beetle in reaction to pine density is not known, we modeled this parameter according to two alternative scenarios. (1) High pine densities are positively correlated with beetle dispersal (scenario hereafter called Pc, "pines as corridors"). In this scenario, a dense pine cover represents a corridor for dispersal due to the large amount of resources available. Conversely, a low pine density would represent a barrier. (2) High pine densities are negatively correlated with beetle dispersal (scenario hereafter called Pr, "pines as resistance"). For this second scenario, it was assumed that a dense pine cover provides sufficient resources for local populations, which would therefore not need to disperse. This scenario assumes 
230 increased dispersal in low pine cover areas. To model resistance based on pine density, we 231 considered the sum of densities of all pine species encountered in a grid cell, because in the Iberian 232 Peninsula, M. galloprovincialis shows no preference for pine species. As shown in previous 233 studies, this beetle will live in the dead wood of any of the pine species considered in this study 234 (Pinus pinaster, P. nigra, P. sylvestris, P. halepensis and P. radiata (Naves et al., 2006; Haran et 235 al., 2015; 2017). Resistance to dispersal was also modeled as a function of the mean minimum

236

237

238

239

240

241

242

243

244

245

246

247

248

249

250

251

252

253

254

255

256

257

258

259

260 temperature (and its proxy: elevation, hereafter called scenarios $\mathrm{T}$ and $\mathrm{E}$ respectively), as low summer temperatures tend to inhibit adult flying activity (Hernández et al., 2011), and because low winter temperatures are likely to determine the survival or the development rate of $M$. galloprovincialis larval instars (Naves \& Sousa 2009). We consider that resistance increases when the annual mean minimum temperatures decrease. We kept temperatures and elevation as distinct environmental features for the analysis, as altitude and temperatures are not similarly correlated in the North and South of Spain.

Resistance distances were computed using the gdistance package (van Etten 2012). Raster layers of environmental features were imported at a resolution of 10 x $10 \mathrm{~km}$. Such a resolution was chosen because the mean flight distance of $M$. galloprovincialis reaches $16 \mathrm{~km}$, based on flight mill experiments (David et al., 2014). Temperature data (1950-2000) were downloaded from Hijmans et al., (2005; http://www.worldclim.org; original resolution: 1 x $1 \mathrm{~km}$ ), the pine density from Tröltzsch et al., (2009; http://www.efi.int/; original resolution: 1 x $1 \mathrm{~km}$ ) and elevation from ARCGIS 9.3 (ESRI, Redlands, CA, USA; original resolution: 1 x $1 \mathrm{~km}$ ). Null distances were not encountered at a grain size of $10 \times 10 \mathrm{~km}$, as none of the sampling sites fell within neighboring sites in the same grain. As temperature, elevation and pine density are continuous parameters, we did not assign particular resistances to particular values, but directly used the values (except for the scenario Pc for which values were set as negative). Pairwise resistance distances were estimated based on random walk probabilities (Chandra et al., 1997, McRae 2006) and computed using the commuteDistance command (gdistance package). Resistance distances were chosen instead of least cost distances (LCD) because they are thought to be more reliable biologically and produce fewer artifacts over long distances (McRae 2006). We constructed a semi matrix of resistance distances between each pair of individuals. Values were normalized to a common scale for further analysis. Collinearity was estimated using the variance inflation factor (VIF) based on 
261 the formula VIF $=1 /\left(1-\mathrm{R}^{2}\right)$, where $\mathrm{R}^{2}$ is the $\mathrm{r}$-squared value of regression between variables. VIF

262 values $>10$ are usually considered evidence for collinearity between environmental features

263 (O'Brien 2007). We did not detect collinearity between environmental features over the whole 264 area of study (VIF $<1$ for all pairwise comparisons).

265

266

267

268

269

270

271

272

273

274

275

276

277

278

279

280

281

282

283

284

285

286

287

288

289

Correlation analysis. We tested correlations between the response (genetic distances matrix, G) and resistance distances (resistance matrices; Isolation By Resistance: IBR) and the geographic distances (Euclidian geographic distance; Isolation By Distance: IBD) using partial Mantel tests (Cushman \& Landguth 2010). Partial Mantel tests measure associations between two distance matrices while partialling out a third distance matrix. We first used simple Mantel tests to correlate IBD with G. We then tested the effect of IBR in partial Mantel tests. Support for the IBR hypothesis was considered when: (1) IBR should be significantly correlated to G after partialling out IBD $(\mathrm{p}<0.05)$ and IBD should be non-significant with IBR partialled out $(\mathrm{p} \geq 0.05$; Cushman et al., 2006). Mantel and partial Mantel tests were performed using the vegan package with $10^{3}$ permutations. This approach is widely used in the field of landscape genetics (Cushman et al., 2006; Cushman and Landguth 2010; Galpern et al., 2012; Castillo et al., 2014) and has been shown to efficiently infer the drivers of gene flow (Cushman \& Landguth 2010b). However, partial Mantel tests have received criticism regarding their statistical performance (Guillot \& Rousset 2013; Diniz-Filho et al., 2013), and are therefore preferably used together with complementary approaches such as ordination methods (Kierepka et al., 2015). To overcome the potential weakness of partial Mantel tests on our dataset, and to validate the statistical significance of correlations, distance matrices were also regressed using commonality analysis (Prunier et al., 2014). This method is based on variance-partitioning and therefore allows the relative importance of the environmental features shaping genetic structure to be estimated, accounting for covariance in the features tested. For the commonality analysis, the response $G$ was regressed onto each resistance matrix separately and each combination using the R yhat package (Nimon et al., 2013).

\section{Resampling on multiple scales and at multiple locations}

The above Partial Mantels test and commonality analysis were conducted in areas of various spatial scales and in various locations in order to estimate the effects of scale and location 
290

291

292

293

294

295

296

297

298

299

300

301

302

303

304

305

306

307

308

309

310

311

312

313

314

315

316

317

318

319

on the inference of the landscape genetic analysis for the four IBR hypothesis (IBR-T, IBR-E, IBR-Pr and IBR-Pc). First, nested sampling areas (sliding windows) were generated over the full extent of the Iberian Peninsula. These areas were constructed as circles of diameters ranging from 220 to $1000 \mathrm{~km}$ (steps of $20 \mathrm{~km}$ ) and centered on each sampling location (scale therefore refers to the extent, Mayer \& Cameron 2003). Mantel tests were performed using all individuals found within each defined area. Areas with a diameter below $220 \mathrm{~km}$ were not included, because it was too small to gather neighboring demes for Mantel tests in the areas with scattered sampling. Then, the statistical support of the landscape analysis performed in the sampling areas generated were compared against their scale and location. The effect of scale was observed by summing the number of areas with a supported IBR hypothesis and computing their mean Mantel $r$ on each scale. The effect of the geographic distribution (location) of sampling areas on the detection of the landscape effect on gene flow was examined by mapping areas with a supported IBR hypothesis. The map was obtained by summing the number of times that each individual was included in a sampling area with IBR hypothesis support among all scales. The values obtained were corrected accounting for intrinsic variation due to overlapping sampling areas. Values at each point were interpolated using the Inverse Distance Weighted (IDW) method in ARCGIS 9.3 (ESRI, Redlands, CA, USA). Given that landscape genetic analyses perform better in a contrasting landscape (i.e. high amplitudes of values of resistant features; Jaquiéry et al., 2011; Cushman et al., 2013), we also sought whether or not support for the IBR hypotheses was due to variations in the environmental features tested. The resistance values of raster cells within each sampling area were extracted and the standard deviation (SD) of those values was computed. We then calculated and compared the mean standard deviation of areas with supported and non-supported IBR hypotheses among the area scales tested. Commonality analyses (see above) were performed within each sampling area generated. As for the Mantel tests, the variation in commonality coefficients (percentage of variance explained by a unique and cumulative IBR hypothesis) was observed by changing the scale and location of the sampling areas. The area maximizing commonality coefficients was chosen for representation of the relative importance of environmental features in shaping genetic structure. All computations were performed using R software version 3.0.2 (R development Core Team 2013). 


\section{Results}

\section{Genotyping}

Overall, 1050 individuals were successfully genotyped. Among the 3 populations of larger sizes tested $(n>19)$, two loci exhibited substantial null allele frequencies $(>7 \%)$ and were therefore not considered for further analysis (Mon 01 and Mon 27). A significant heterozygote deficit was detected at four loci (Mon 30, 35, 42, 44). Corresponding null allele frequencies were low ( $<7 \%)$, so these loci were kept. After the removal of incomplete genotypes $(n=58)$ and biased loci, we obtained a total of 992 individuals genotyped at ten loci. The average number of alleles per locus was 10.2 (range: 6-24). The number of alleles per deme (using rarefaction) ranged from 1.32 to 1.64 and $F_{i s}$ estimates from -0.27 to 0.38 (Table S1).

\section{Genetic structure}

Individuals formed an optimum number of two clusters under STRUCTURE analysis (Figure S3). The clusters showed a clear geographic structure, exhibiting a split between Portugal and western Galicia (West Iberian cluster) versus the rest of the Iberian Peninsula (Fig. 1A). The PCA gave similar results on the first axis (eigenvalue: 0.494 accounting for $14.3 \%$ of the total inertia), splitting demes into two distinct clusters (Fig. 1C). Estimates of population differentiation $\left(F_{s t}\right)$ between the three populations of large size $(\mathrm{n}>19)$ were moderate (Castro Daire /Catsellbell: 0.13; Castro Daire/Vale Feitoso: 0.13; Catsellbell/Vale Feitoso: 0.05; $\mathrm{p}<0.001$ ).

The data points of the variogram were grouped into 26 distance classes ranging from 0 to $1252 \mathrm{~km}$, with a distance interval of $50 \mathrm{~km}$. The variogram revealed that the first axis of the PCA corresponded to a highly spatially structured pattern (Fig. 2). The semi-variance first progressively increased with increasing lag distance up to a distance of about $190 \mathrm{~km}$ and then reached a plateau. For distances of about $400 \mathrm{~km}$, the semi-variance increased again and leveled off for distances further than $1000 \mathrm{~km}$. The resulting plateau of the variogram showed the presence of a long-range spatial variation superimposed over a more local, i.e. short-scale genetic structure, occurring on scales of 200 to $400 \mathrm{~km}$. For scales below $200 \mathrm{~km}$, the variogram showed that genotypes were strongly spatially auto-correlated (i.e. non-independent). 
Analyses were conducted on both the whole dataset (992 individuals, 132 localities) and

351

352

353

354

355

356

357

358

359

360

361

362

363

364

365

366

367

368

369

370

371

372

373

374

375

376

Over the whole study area (whole dataset), we generated a total of 30,576 sampling areas. The mean number of individuals within sampling areas varied from 89.18 (SD: 42.42) on the smallest scale $(220 \mathrm{~km})$ to 644.58 (SD: 158.07) on the largest scale (1000 km; Fig. S2). Significant effects of environmental features were detected for all IBR hypotheses tested with partial Mantel tests, but the frequency of areas exhibiting an IBR effect varied between scales and locations (Fig. 3A). Significant effects of environmental features were detected for the IBR-E, IBR-Pr and IBRT hypotheses in about $15-25 \%$ of the areas on the smallest scale $(220-300 \mathrm{~km})$. The frequency of IBR-E and IBR-Pr gradually increased to reach $97 \%$ and $70 \%$ for areas of $1000 \mathrm{~km}$. The frequency of areas with a supported IBR-T hypothesis increased between scales to reach a peak around 600 $\mathrm{km}(82 \%$ of areas) and subsequently decreased. Significant IBR-Pc hypotheses were encountered at a lower frequency. The number of areas with a positive effect of the Pc hypothesis was 4.07 areas, on average, for all the scales considered. Significant isolation by distance (IBD) was observed for $60 \%$ of areas on the smallest scale. A first plateau of about $85 \%$ of areas was reached for scales ranging between 400 and $700 \mathrm{~km}$, and a second plateau of almost 100\% of areas was reached for scales above $700 \mathrm{~km}$. Mean Mantel $\mathrm{r}$ values for areas with a supported IBR hypothesis ranked between 0.05 and 0.25 and generally decreased when the scale increased (Fig. 3B). Hypothesis IBR-T showed the highest mean Mantel $r$ value out of all the IBR hypotheses for scales above $360 \mathrm{Km}$.

Interpolation of supported IBR hypotheses and IBD was based on areas of scales ranging from 220 to $600 \mathrm{~km}$, because most of the variation in the detection of the effects of environmental features was found on these scales (Fig. 3A). For most IBR hypotheses (IBR-E, IBR-Pr and IBRT) and IBD, the effects were mainly detected in the northern part of the study area (Fig. 4). In contrast, these IBR hypotheses were the least frequently detected on the southern and eastern sides of the Iberian Peninsula. For the IBR-Pc hypothesis, significant effects were detected mainly in 
377 Andalucía, along the Betic system. Conversely, low or no effects for this hypothesis were detected

378 in the northern half of the Iberian Peninsula. The distribution of supported hypotheses was similar

379 for those performed on the whole dataset and on the Spanish cluster only (Fig. 4). For hypotheses

380 IBR-E, IBR-Pr and IBR-Pc, the variation of environmental features was lower on average in areas

381 exhibiting significant effects for scales up to 400 - $600 \mathrm{~km}$ (whole dataset; Fig. 5). Above this

382 scale, the mean standard deviation (SD) of areas with a supported IBR hypothesis was either equal

383 to or higher than the mean SD of areas with no support. For the IBR-T hypothesis, the mean SD

384 of areas with support was above the mean for non-supported areas, for most of the scales. The

385 results of the commonality analysis were in agreement with those of the Mantel tests. The IBR-T

386 and IBR-Pr hypotheses purely contributed to most of the total variance explained (20.77 to $32.65 \%$

387 and 21.82 to $35.24 \%$, respectively, Table 1), and the highest contribution to the total variance

388 explained was observed for the joint effects of IBR-E and IBR-T (54.31 to 56.43\%). Conversely,

389 the IBR-Pc hypothesis made a limited contribution to the variance explained in pure effect (1.80

390 to $3.81 \%$ ). As for the Mantel tests, the sampling areas showing the maximum explained variance

391 over all sampling areas (20.9 to 24\%) were located in the western and northern parts of the Iberian

392 Peninsula and had a medium diameter (520 to $620 \mathrm{~km})$.

393

394

\section{Discussion:}

395

396

The landscape genetics approach seeks to infer general drivers of gene flow for species in a heterogeneous landscape context (Manel \& Holderegger 2013). However, the ability of this

397

398

399

400

401

402

403

404

405 approach to make inferences about the effect of environmental features may vary due to multiple evolutionary processes acting on the genetic structure of organisms on different spatial and temporal scales. In this study, we explored potential barriers against and corridors for the dispersal and gene flow of a flying insect in a large area with dramatic landscape changes. Based on multiscale and multi-site resampling of study areas, we successfully identified the effects of environmental features on gene flow for independent study areas, and for different inference methods. Resampling provided a quantitative value for the results, making it possible to control the Type-1 errors associated with the inference methods employed (Shortbull et al. 2011). Apart from identifying relevant environmental features, the resampling method showed patterns for the 
406 frequency at which landscape effects were detected among locations, especially on the smallest 407 spatial scales. Interestingly, most of these patterns could be explained by the biology of the species

408

409

410

411

412

413

414

415

416

417

418

419

420

421

422

423

424

425

426

427

428

429

430

431

432

433

434

435

\section{Importance of the scale of the study area for flying insects}

We observed a notable influence of scale on the detection of supported IBR hypotheses with Mantel tests for most of the environmental features tested (IBR-E, IBR-T and IBR-Pr). Support was scarcely detected on the smallest spatial scale $(220-400 \mathrm{~km})$ and was generally more often detected with increasing scale. A larger study area had a larger sampling leading to better detection of positive correlations via partial Mantel tests (Cushman \& Landguth 2010; Landguth et al. 2012). Beyond the simple effect of the sampling size, the spatial scale of gene flow and resulting genetic structure also influenced the inference of the hypothesis tested. The smallest spatial scales of $190-400 \mathrm{~km}$ corresponded to the distances at which the variogram showed an initial plateau of genetic dissimilarity (Figure 2). This correspondence suggested that for this range of scales, the dissimilarity between individuals of $M$. galloprovincialis was not enough to show a significant effect of environmental features on gene flow in most study areas. In contrast, the peak (for IBR-T) or inflection of the curves (for IBR-Pr, IBR-E) of the number of areas with supported IBR hypotheses observed on scales ranging from 400 to $600 \mathrm{~km}$ corresponded to the increase in dissimilarity in the variogram (Figure 2). Thus, scales above $400 \mathrm{~km}$ seemed more appropriate for observing a genetic structure of $M$. galloprovincialis potentially structured by environmental features. Interestingly, we found that the variation in the frequency of areas with support was specific to each environmental feature tested. In line with previous studies on large mammals (Zeller et al., 2014) and on insects (Rasic and Keyghobadi 2012), this study highlighted that each environmental feature affected gene flow on a distinct scale, and that empirical studies including several features should always consider a range of study scales.

Weak support of the IBR hypothesis on a small scale illustrated a general problem of the landscape genetic analysis performed on flying species, which are naturally less affected by environmental features than non-flying species. For such species, the combination of intensive dispersal and associated gene flow and a limited number of environmental features affecting 
436 dispersal makes inference difficult on small spatial scales (Dreier et al., 2014). In the Monochamus

437 species, substantial flying distances have been measured (up to $22 \mathrm{~km}$ in the field: Takasu et al., 438 2000; Linit \& Akbulut 2003; Hernandez et al., 2011; Gallego et al., 2012; Mas et al., 2013; David 439 et al., 2014), causing strong inbreeding of populations and leading to a weak local genetic structure 440 (Kawai et al., 2006; Shoda-Kagaya 2007; Haran et al., 2015). Considering a continuous range of 441 scales in the analysis prevented us from basing our conclusions on a scale for which the effect of

442

443

444

445 environmental features could not be detected. In this respect, an experimental design for flying insect species should follow the approaches used for large mammals, for which multiple scales, including very large scales, have been used to account for a scale of gene flow that is unknown a priori (Galpern et al., 2012; Zeller et al., 2014).

\section{Effect of geographic location on inference}

Based on the resampling of study areas in the East Iberian cluster, we observed the existence of heterogeneous geographic distribution of supported resistance models (IBR-T, IBR$\mathrm{E}$ and IBR-Pr). Most variation in the distribution of support for IBR was observed on small and intermediate scales $(220-600 \mathrm{~km})$, the smallest scale being larger than areas at which landscape genetic analysis are usually conducted (Shortbull et al. 2011, Zeller et al. 2012). On these scales, supported effects were mainly detected in the northern-central part of the Iberian Peninsula. Conversely, effects were less supported in the rest of the Iberian Peninsula (center, south and coasts). Variation of support are known to occur when multiple area of study are tested in landscape genetics (Shortbull et al. 2011), however, in this case all areas with an effect were located in the same region. These results highlighted that the genetic structure of $M$. galloprovincialis was structured according to the environmental features tested in some areas but not in others, independently of variations in the heterogeneity of the environmental features (Figure 5). This observation is interesting, because one might expect a native species such as $M$. galloprovincialis to have homogeneous dispersal in response to environmental features, at least within a genetic lineage, and that this effect would be detected homogeneously across a study area. Determining the exact origin of such heterogeneity is challenging. It is suggested that this variation was a legacy of changes in the distribution of host trees in the Iberian Peninsula. Indeed, the distribution and density of pine trees have been strongly affected by anthropogenic activities over recent centuries (Ruiz-Benito et al., 2012; Lopez-Merino et al., 2014), resulting in local extinction, 
466 as well as the connectivity and fragmentation of pine tree cover over time. For example, Abel-

467 Schaad et al., (2014) showed that pine trees locally disappeared from the Central Iberian System 468 during the middle ages. In contrast, these areas were $80 \%$ afforested with pines trees over the 19404691950 period. It is assumed that such recent modifications have dramatically affected the 470 distribution and abundance of $M$. galloprovincialis, and that the time since these modifications 471 occurred is too short to have affected the genetic structure of the beetle according to the 472 environmental features tested (Epps \& Keyghobadi 2015).

473 This study also highlighted empirically how important it is to account for the genetic 474 differentiation of the species derived from evolutionary history when selecting the location of a 475 study area. We found that the effect of environmental features on gene flow was not detected in 476 study areas mainly located along the western Iberian coast, and these areas always overlapped the 477 West and East Iberian genetic clusters. In these cases, substantial genetic differentiation blurred 478 the genetic structure derived from the effect of environmental features on gene flow, which is more 479 recent and weaker in $M$. galloprovincialis. This effect of differentiated genetic clusters on 480 inference was also observed in the strength of the correlations: we observed a decrease in the mean 481 Mantel $\mathrm{r}$ for large-scale study areas (600-1000 km) which always overlapped the two genetic 482 clusters. It is difficult to predict exactly to what extent genetic divergence derived from 483 484 evolutionary history can contribute, or not, to the detection of an effect of environmental features on gene flow, as this structure can also derive from old and stable barriers to dispersal. While the vast majority of species exhibit differentiated genetic linages derived from evolutionary history (Hewitt, 2000), the genetic structure of a species beyond the extent of the study area is rarely explored in landscape genetic analysis (Zeller et al. 2012). Our results suggest that carrying out analyses both within each genetic cluster and over the whole dataset is preferable, to avoid the confounding effect of evolutionary history on landscape genetic analyses.

\section{Relevance of inference for the model species}

This study enabled us to generalize patterns of dispersal for M. galloprovincialis and confirmed previous observations made on the biology and ecology of this species. Mantel tests and a commonality analysis supported the hypothesis that elevated areas and their associated 
496 corroborates the observations made for the congeneric species M. alternatus across the Ohu chain 497 of mountains in Japan (Shoda-Kagaya 2007) and on M. galloprovincialis across the Pyrenees 498 (Haran et al., 2015; 2017). In addition, this hypothesis tends to be confirmed by several studies 499 showing that M. galloprovincialis larva development and survival (Naves and Sousa 2009), and 500 its ability to complete its development within one or two years (Tomminen 1993; Naves et al., 501 2007b; Koutroumpa et al., 2008), are affected by low temperatures. Lastly, the adult flying activity 502 of this beetle was shown to be negatively affected by low daily temperatures (Hernández et al., 503 2011), and to be directed mainly down-hill (Torrez-Vila et al., 2015). Our analysis also supports 504 the hypothesis that M. galloprovincialis exhibits limited dispersal when pine trees are abundant. 505 This species is known to develop on dead branches stemming from a self-pruning process 506 encountered in pines (Mäkinen 1999). Dead branches represent a resource that is quite well 507 distributed in space and time in pine stands. Such an abundance of resource is thought to cause 508 limited dispersal in adults. The philopatric behavior of $M$. galloprovincialis in relation to available 509 resources is consistent with flight observations of this species in the field (Torres-Vila et al., 2015), 510 or with the behavior of the pine processionary moth (Thaumetopoea pityocampa), another 511 oligophagous pine-associated insect (Demolin 1969). Conversely, the Pr hypothesis suggested 512 that low pine densities are not barriers to dispersal. This is in agreement with the suggestions of 513 Torres-Vila et al., (2015) that the dispersal of M. galloprovincialis tends to be enhanced across 514 open areas. Rossi et al., (2016) showed that areas without pine forests still show a homogeneous 515 distribution of scattered trees planted for ornamental use using observed and simulated data. We 516 suggest that pine trees outside forests provide a scattered but homogeneously distributed resource 517 that allows the dispersal of M. galloprovincialis across non-forested areas.

\section{Conclusions}

Our results show the importance of simultaneously considering a continuous range of scales and multiple locations when exploring the effect of environmental features on dispersal in

522 highly mobile species. Multiple scales allow the effect of environmental features to be inferred at 523 the appropriate extent for each feature tested, while preventing the analysis from being focused on 524 an extent where intensive gene flow makes inference impossible due to the lack of genetic 
525 structure. In addition, resampling of the study area across multiple locations helped to identify

526 variation in inference due to conflicting signals in genetic structure, and thereby allowed for

527 generalizing conclusions regarding the effects of environmental features on dispersal and gene

528 flow. As a result, the combination of a resampled study area on multiple spatial scales across

529 various locations in a landscape genetic analysis provides a more general picture of the effects of 530 environmental features on the gene flow of organisms and has the power to reduce the variability 531 of results while limiting the sampling effort.

532

\section{Acknowledgments}

534

535

536

537

538

539

540

541

542

543

544

545

546

547

548

549

550

551

552 Figure captions
We warmly thank Rolf Holderegger and Bertrand Gauffre for valuable comments on the early versions of this manuscript. We also thank Jérôme Rousselet and Christelle Robinet for interesting exchanges and help regarding the methodology and Peter Biggins for English editing.

Table 1: Commonality coefficients of both unique and common effects for the three sampling areas with the highest variance explained. Code pop: population code for the center of the sampling area. Scale: diameter of sampling area $(\mathrm{km}) . N$ : number of individuals in sampling area. Coef.: percentage of variance explained by environmental features (IBR hypotheses). \% Total: percentage of the contribution of environmental features to the total variance explained. Environmental features and their associated Isolation By Resistance (IBR) hypothesis: E: elevation model (high elevations $=$ resistance to dispersal). $P_{c}$ : Pine density model (high pine density = corridors to dispersal. $\mathrm{Pr}$ : reversed pine density model (high pine density = resistance to dispersal). $T$ : temperature model (low minimum annual temperatures $=$ resistance to dispersal). 
553 Figure 1: Genetic clustering of 992 individuals of Monochamus galloprovincialis sampled at 132 554 locations. A: Assignment of individuals to clusters based on a STRUCTURE analysis for K=2. B: 555 Assignment of demes to clusters for $\mathrm{k}=2$, displayed in geographic context (Iberian Peninsula, the 556 size of the pies refers to the size of the demes). C: PCA of individuals on first and second axes, 557 colors and ellipses refer to demes.

558 Figure 2: Empirical semi-variogram of genotypes of Monochamus galloprovincialis. The 559 variogram was fitted with an exponential model to highlight the first plateau. Data points are shown 560 with a spatial lag distance of $50 \mathrm{~km}$.

561 Figure 3: Percentage of areas with supported IBR hypotheses for Mantel tests (A) and mean 562 partial Mantel $r(B)$ of areas with support for the IBR hypotheses $(p<0.05)$ with increasing scales 563 (whole dataset). E: Elevation, $T$ : Mean minimum temperatures, $P r$ and $P c$ : pine densities as a 564 resistant feature and as a corridor respectively, IBD: Isolation by distance.

565 Figure 4: Distribution of supported IBR hypotheses through Mantel tests for the environmental 566 features tested (IBD: Euclidian distances; $T$ : mean minimum temperatures; E: elevation; Pr: high 567 pine densities as barriers; $P c$ : high pine densities as corridors). Gray maps (A) refer to the 568 distribution of environmental features associated with resistance models (From white to black: low 569 to high resistance values). Colored maps refer to interpolations of supported IBR hypotheses on 570 the whole dataset (B) and within the western Iberian cluster only (C). From blue to red: low to 571 high frequency of study areas with supported resistance models.

572 Figure 5: Spatial heterogeneity (mean standard deviation, SD) of environmental features in areas 573 with supported and non-supported resistance hypotheses through Mantel tests with increasing 574 scales. Mean SD: mean standard deviation. T: mean minimum temperatures (A); E: elevation (B); $575 P r$ : high pine densities as barriers (C); $P c$ : high pine densities as corridors (D). sig: significant, 576 non-sig: non-significant.

\section{References}

580

581

582

583

584

585
Abel-Scaad D, Lopez-Saez JA, Pulido F. 2014. Heathlands, fire and grazing. A paleoenvironmental view of Las Hurdes (Cáceres, Spain) history during the last 1200 years. Forest Systems 23:247-258.

Anderson CD, Epperson BR, Fortin MJ, Holderegger R, James PMA, Rosenberg MS, Scribner KT, Spear S. 2010. Considering spatial and temporal scale in landscape-genetic studies of gene flow. Molecular Ecology 19:3565-3575. 
586

587

588

589

590

591

592

593

594

595

596

597

598

599

600

601

602

603

604

605

606

607

608

609

610

611

612

613

614

615

616

617

618

619

620

621

622

623

624

625

Angelone S, Kienast F, Holderegger R. 2011. Where movement happens: scale-dependent landscape effects on genetic differentiation in the European tree frog. Ecography 34:714722.

Burrough PA. 1983. Problems of superimposed effects in statistical study of the spatial variation in soil. Agricultural Water Management 6:123-143.

Castillo JA, Epps CW, Davis AR, Cushman SA. 2014. Landscape effects on gene flow for a climate-sensitive montane species, the American pika. Molecular Ecology 23:843-856.

Chandra AK, Raghavan P, Ruzzo WL, Smolensky R, Tiwari P. 1997. The electrical resistance of a graph captures its commute and cover times. Computational Complexity 6:312-340.

Chapuis MP, Estoup A. 2007. Microsatellite null alleles and estimation of population differentiation. Molecular Biology and Evolution 24:621-631.

Cushman SA, Landguth E. 2010. Scale dependent inference in landscape genetics. Landscape Ecology 25:967-979.

Cushman SA, McKelvey KS, Hayden J, Schwartz MK. 2006. Geneflow in complex landscapes: testing multiple models with causal modeling. American Naturalist 168:486-499.

Cushman SA, Shirk AJ, Landguth E. 2013. Landscape genetics and limiting factors. Conservation Genetics 14:263-274.

David G, Giffard B, Piou D, Jactel H. 2014. Dispersal capacity of Monochamus galloprovincialis, the European vector of the pine wood nematode, on flight mills. Journal of Applied Entomology 138:566-576.

Démolin G. 1969. Comportement des adultes de Thaumetopoea pityocampa Schiff. Dispersion spatiale, importance écologique. Annales des Sciences Forestières 26:89-102.

Diniz-Filho JAF, Soares TN, Lima JS, Dobrovoski R, Landeiro VL, Telles MPD, Rangel TF, Bini LM. Mantel test in population genetics. Genetics and Molecular Biology 36:475-485.

Dreier S, Redhead JW, Warren IA, Bourke AF, Heard MS, Jordan WC, Sumner S, Wang JL, Carvell C. 2014. Fine-scale spatial genetic structure of common and declining bumble bees across an agricultural landscape. Molecular Ecology 23:3384-3395.

Drizen K, Adriaensen F, Rondinini C, Doncaster CP, Matthysen E. 2007. Evaluating least-cost model predictions with empirical dispersal data: a case-study using radiotracking data of hedgehogs (Erinaceus europaeus). Ecological Modelling 209:314-322.

Dudaniec RY, Rhodes JR, Wilmer JW, Lyons M, Lee KE, McAlpine CA, Carrick FN. 2013. Using multilevel models to identify drivers of landscape-genetic structure among management areas. Molecular Ecology 22:3752-3765.

Earl DA, VonHoldt BM. 2012. STRUCTURE HARVESTER: a website and program for visualizing STRUCTURE output and implementing the Evanno method. Conservation Genetics Resources 4:359 361.

Epps CW, Keyghobadi N. 2015. Landscape genetics in a changing world: disentangling historical and contemporary influences and inferring change. Molecular Ecology 24:6021-6040.

Evanno G, Regnaut S, Goudet J. 2005. Detecting the number of clusters of individuals using the software structure: a simulation study. Molecular Ecology 14:2611-2620. 
626

627

628

629

630

631

632

633

634

635

636

637

638

639

640

641

642

643

644

645

646

647

648

649

650

651

652

653

654

655

656

657

658

659

660

661

662

663

664

Gallego D, Sanchez-Garcia FJ, Mas H, Campo MT, Lencina YJL. 2012. Estudio de la capacidad de vuelo a larga distancia de Monochamus galloprovincialis (Olivier 1795). (Coleoptera: Cerambycidae) en un mosaico agro-forestal., Boletin de Sanidad Vegetal Plagas 38:109123.

Galpern P, Manseau M, Wilson P. 2012. Grains of connectivity: analysis at multiple spatial scales in landscape genetics. Molecular Ecology 21:3996-4009.

Guillot G, Leblois R, Coulon A, Frantz AC. 2009. Statistical methods in spatial genetics. Molecular Ecology. 18: 4734-4756.

Goovaerts P. 1997. Geostatistics for Natural Resources Evaluation. Oxford University Press, Oxford.

Guillot G, Rousset F. 2013. Dismantling the Mantel tests. Methods in Ecology and Evolution 4:336-344.

Haran J, Rousselet J, Tellez D, Roques A, Roux G. 2017. Phylogeography of Monochamus galloprovincialis, the European vector of the pinewood nematode. Journal of Pest Science. doi: 10.1007/s10340-017-0878-4.

Haran J, Roques A, Barnard A, Robinet C, Roux G. 2015. Altitudinal barrier to the spread of an invasive species: could the Pyrenean chain slow the natural spread of the pine wood nematode? PLoS ONE 10(7):e0134126.

Haran J, Roux-Morabito G. 2014. Development of 12 microsatellites loci for the longhorn beetle Monochamus galloprovincialis (Coleoptera Cerambycidae), vector of the pinewood nematode in Europe. Conservation Genetics Resources 6:975-977.

Hellrigl KG. 1971. La bionomie des espèces de Monochamus (Coleoptera, Cerambycidae) et leur importance pour la sylviculture et l'économie du bois. Redia 52:367-511.

Hernández R, Ortiz A, Pérez V, Gil JM, Sanchez G. 2011. Monochamus galloprovincialis (Olivier, 1795) (Coleoptera: Cerambycidae), comportamiento y distancias de vuelo. Boletin de Sanidad Vegetal Plagas 37:79-96.

Hewitt GM. 2000. The genetic legacy of the Quaternary ice ages. Nature 405:907-913.

Hijmans RJ, Cameron SE, Parra JL, Jones PG, Jarvis A. 2005. Very high resolution interpolated climate surfaces for global land areas. International Journal of Climatology 25:1965-1978.

Holderegger R, Wagner HH. 2008. Landscape genetics. BioScience 58:199-207.

Jaquiéry J, Broquet T, Hirzel AH, Yearsley J, Perrin N. 2011. Inferring landscape effects on dispersal from genetic distances: how far can we go? Molecular Ecology 20:692-705.

Jactel H, Castagnone P, Mota M, Robinet C, Roux G, Sarniguet C. 2015. Evaluation of emergency measures to prevent the spread of the pine wood nematode within the European Union. ANSES opinion, Collective Expert Appraisal Report, 61 pp.

Jombart T. 2008. ADEGENET: a R package for the multivariate analysis of genetic markers. Bioinformatics 24:1403-1405.

Kalinowski S. 2005. HP-RARE 1.0: a computer program for performing rarefaction on measures of allelic richness. Molecular Ecology Notes 5:187-189. 
665

666

667

668

669

670

671

672

673

674

675

676

677

678

679

680

681

682

683

684

685

686

687

688

689

690

691

692

693

694

695

696

697

698

699

700

701

702

703

Kawai M, Shoda-Kagaya E, Maehara T, Zhou ZH, Lian CL, Iwata R, Yamane A, Hogetsu T. 2006. Genetic structure of pine sawyer Monochamus alternatus (Coleoptera: Cerambycidae) populations in northeast Asia: Consequences of the spread of pine wilt disease. Environmental Entomology 35:569-579.

Keller D, Holderegger R, van Strien MJ. 2013. Spatial scale affects landscape genetic analysis of a wetland grasshopper. Molecular Ecology 22:2467-2482.

Kierepka EM, Latchi EK. 2015. Performance of partial statistics in individual-based landscape genetics. Molecular Ecology 15:512-525.

Kindall JL, Van Manen FT. 2007. Identifying habitat linkages for American black bears in North Carolina, USA. Journal of Wildlife Managment 71:487-495.

Koutroumpa F, VincentB, Roux-Morabito G, Martin C, Lieutier F. 2008. Fecundity and larval development of Monochamus galloprovincialis (Coleoptera Cerambycidae) in experimental breeding. Annals of Forest Science 65:707.

Legendre P, Legendre L. 1998. Numerical Ecology. Elsevier, Amsterdam.

Linit MJ, Akbulut S. 2003. Pine wood nematode phoresis: the impact on Monochamus carolinensis life functions. Nematology Monographs and Perspectives 1:227-237.

Lopez-Merino L, Martinez Cortizas A, Reher GS, Lopez-Saez JA, Mighall TM, Bindler R. 2014. Reconstructing the impact of human activities in a NW Iberian Roman mining landscape for the last 2500 years. Journal of Archaeological Science 50:208-218.

Mäkinen H. 1999. Growth, suppression, and self-pruning of branches of Scots pine in southern and central Finland. Canadian Journal of Forest Research 29:585-594.

Manel S, Holderegger R. 2013. Ten years of landscape genetics. Trends in Ecology and Evolution 28:614-621.

Manel S, Schwartz MK, Luikart G, Taberlet P. 2003. Landscape genetics: combining landscape ecology and population genetics. Trends in Ecology and Evolution 18:189-197.

Mas H, Hernandez R, Villaroya G, Sanchez G, Pérez-Laorga E, González E, Ortiz A, Lencina JL, Rovira J, Marco M, Pérez V, Gil M, Sánchez-García FJ, Bordón P, Pastor C, Biel MJ, Montagud L, Gallego D. 2013. Dispersal behavior and long distance flight capacity of Monochamus galloprovincialis (Olivier 1795), In: Schröder, T (ed.), Pine Wilt Disease Conference 2013, pp. 22, Braunschweig, ISSN: 1866-590X.

Mayer AL, Cameron GN. 2003. Consideration of grain and extent in landscape studies of terrestrial vertebrate ecology. Landscape and Urban Planning 65:201 - 217.

McRae B. 2006. Isolation by Resistance. Evolution 60:1551-1561.

Naves P, de Sousa E. 2009. Threshold temperatures and degree-day estimates for development of post-dormancy larvae of Monochamus galloprovincialis (Coleoptera: Cerambycidae). Journal of Pest Science 82:1-6.

Naves PM, Camacho S, de Sousa E, Quartau JA. 2007. Transmission of the pine wood nematode Bursaphelenchus xylophilus through oviposition activity of Monochamus galloprovincialis (Coleoptera : Cerambycidae). Entomologica Fennica 18:193-198. 
704

705

706

707

708

709

710

711

712

713

714

715

716

717

718

719

720

721

722

723

724

725

726

727

728

729

730

731

732

733

734

735

736

737

738

739

740

741

Naves P, Sousa E, Quartau J. 2006. Feeding and oviposition preferences of Monochamus galloprovincialis for some conifers under laboratory conditions. Entomologica Experimentalis et Applicata 120:99-104.

Nimon K, Oswald F, Roberts JK. 2013. yhat: Interpreting Regression Effects. R package version 2.0-0.

O'Brien RM (2007. A caution regarding rules of thumb for variance inflation factors. Quality and Quantity 41:673-690.

Oksanen J, Blanchet FG, Kindt R, Legendre P, Minchin PR, O'Hara RB, Simpson GL, Solymos P, Stevens MHH, Szoecs E, Wagner H. 2016. vegan: Community Ecology Package. R package version 2.3-3. http://CRAN.R-project.org/package=vegan

Pflüger FJ, Balkenhol N. 2014. A plea for simultaneously considering matrix quality and local environmental conditions when analyzing landscape impacts on effective dispersal. Molecular Ecology 23:2146-2156.

Pritchard JK, Stephens M, Donnelly P. 2000. Inference of population structure using multilocus genotype data. Genetics 155:945-959.

Prunier JG, Colyn M, Legendre X, Nimon KF, Flamand MC. 2014. Multicollinearity in spatial genetics: separating the wheat from the chaff using commonality analyses. Molecular Ecology 24:263-283.

Prunier JG, Kaufmann B, Fenet S, Picard D, Pompanon F, Joly P. 2013. Optimizing the trade-off between spatial and genetic sampling efforts in patchy populations: towards a better assessment of functional connectivity using an individual-based sampling scheme. Molecular Ecology 22:5516-5530.

Rasic G, Keyghobadi N. 2012. From broad scale patterns to fine-scale processes: habitat structure influences genetic differentiation in the pitcher plant midge across multiple spatial scales. Molecular Ecology 21:223-236.

Raymond M, Rousset F. 1995. GENEPOP (version 1.2): population genetics software for exact tests and ecumenicism. Journal of Heredity 86:248-249.

R Development Core Team. 2013. R: a language and environment for statistical computing. $\mathrm{R}$ Foundation for Statistical Computing, Vienna, Austria. https://www.R-project.org/.

Ribeiro PJ, Diggle PJ. 2001. geoR: a package for geostatistical analysis. R-NEWS 1, 14-18.

Robertson GP, Gross KL. 1994. Assessing the heterogeneity of belowground resources: quantifying pattern and scale. In: Caldwell M, Pearcy R (eds.), Exploitation of Environmental Heterogeneity by Plants. Academic Press, pp. 237-253.

Rossi JP. 2003. Short-range structures in earthworm spatial distribution. Pedobiologia 47:582587.

Rossi JP, Garcia J, Roques A, Rousselet J. 2016. Trees outside forests in agricultural landscapes: spatial distribution and impact on habitat connectivity for forest organisms. Landscape Ecology 31:243-254. 
742

743

744

745

746

747

748

749

750

751

752

753

754

755

756

757

758

759

760

761

762

763

764

765

766

767

768

769

770

771

772

773

774

775

776

777

778

779

780

781

Ruiz-Benito P, Gomez-Aparicio L, Zavala MA. 2012. Large-scale assessment of regeneration and diversity in Mediterranean planted pine forests along ecological gradients. Diversity and Distributions 18:1092-1106.

Serra P, Vera A, Francesc Tulla A, Salvati L. 2014. Beyond urbanerural dichotomy: exploring socioeconomic and land-use processes of change in Spain (1991-2011). Applied Geograpy 55:71-81.

Sexton JP, Hangartner SB, Hoffmann AA. 2014. Genetic isolation by environment or distance: which pattern of gene flow is most common? Evolution 68:1-15.

Shirk AJ, Wallin DO, Cushman SA, Rice CG, Warheit KI. 2010. Inferring landscape effects on gene flow: a new model selection framework. Molecular Ecology 19:3603-3619.

Shoda-Kagaya E. 2007. Genetic differentiation of the pine wilt disease vector Monochamus alternatus (Coleoptera: Cerambycidae) over a mountain range - revealed from microsatellite DNA markers. Bulletin of Entomological Research 97:167-174.

Short Bull RA, Cushman SA, Mace R, Chilton T, Kendall KC, Landguth EL, Schwartz MK, McKelvey K, Allendorf FW, Luikart G. 2011. Why replication is important in landscape genetics: American black bear in the Rocky Mountains. Molecular Ecology 20:1092-1107.

Sjöstedt-de Luna, S., 2001. Resampling non-homogeneous spatial data with smoothly varying mean values. Statistics \& Probability Letters 53, 373-379. doi:10.1016/S01677152(01)00040-2

Storey JD. 2002. A direct approach to false discovery rates. Journal of the Royal Statistical Society: Series B 64:479-498.

Storfer A, Murphy MA, Evans JS, Goldberg CS, Robinson S, Spear SF. 2007. Putting the "landscape" in landscape genetics. Heredity 98:128-142.

Takasu F, Yamamoto N, Kawasaki K, Togashi K, Kishi Y, Shigesada N. 2000. Modeling the expansion of an introduced tree disease. Biological Invasions 2:141-150.

Tomminen J. 1993. Development of Monochamus galloprovincialis Olivier (Coleoptera, Cerambycidae) in cut trees of young pines (Pinus sylvestris L.) and log bolts in southern Finland. Entomologica Fennica 4:137-142.

Torres-Vila L, Zugasti C, De-Juan JM, Olivia MJ, Montero C, Mendiola FJ, Conejo Y, Sanchez A, Fernandez F, Ponce F, Esparrago G. 2015. Mark-recapture of Monochamus galloprovincialis with semiochemical-baited traps: population density, attraction distance, flight behavior and mass trapping efficiency. Forestry 88:224-236.

Tröltzsch K, Van Brusselen J, Schuck A. 2009. Spatial occurence of the major tree species group in Europe derived from multiple data sources. Forest Ecology and Management 257:294302.

van Etten J. 2012. GDISTANCE: distances and routes on geographical grids. R package version 1.1-4.

Van Strien MJ, Keller D, Holderegger R, Ghazoul J, Kienast F, Bolliger J. 2014. Landscape genetics as a tool for conservation planning: predicting the effects of landscape change on gene flow. Ecological Applications 24:327-339. 
782

783

784

785

786

787

788

789

790

791

792

793

794

795

796

797

798

799

800

801

802

803

804

805

806

807

808

809

810

811

812

813

814

815

816

817

818

819

820

821

822

823

824

825

826

827

Waters JM, Fraser CI, Hewitt GM. 2013. Founder takes all: density-dependent processes structure biodiversity. Trends in Ecology and Evolution 28:78-85.

Wagner HH, Holderegger R, Werth S, Gugerli F, Hoebee SE, Scheidegger C. 2005. Variogram analysis of the spatial genetic structure of continuous populations using multilocus microsatellite data. Genetics 169:1739-1752.

Zalewski A, Piertney SB, Zalewska H, Lambin X. 2009. Landscape barriers reduce gene flow in an invasive carnivore: geographical and local genetic structure of American mink in Scotland. Molecular Ecology 18:1601-1615.

Zeller KA, McGarigal K, Beier P, Cushman SA, Winston Vickers T, Boyce WM. 2014. Sensitivity of landscape resistance estimates based on point selection functions to scale and behavioral state: pumas as a case study. Landscape Ecology 29:541-557.

Zeller KA, McGarigal K, Whiteley AR. 2012. Estimating landscape resistance to movement: a review. Landscape Ecology 27:777-797.

Zellmer AJ, Knowles LL. 2009. Disentangling the effects of historic vs. contemporary landscape structure on population genetic divergence. Molecular Ecology 18:3593-3602.

\section{Appendices}

Appendix 1: R script detailing the approach used in this study.

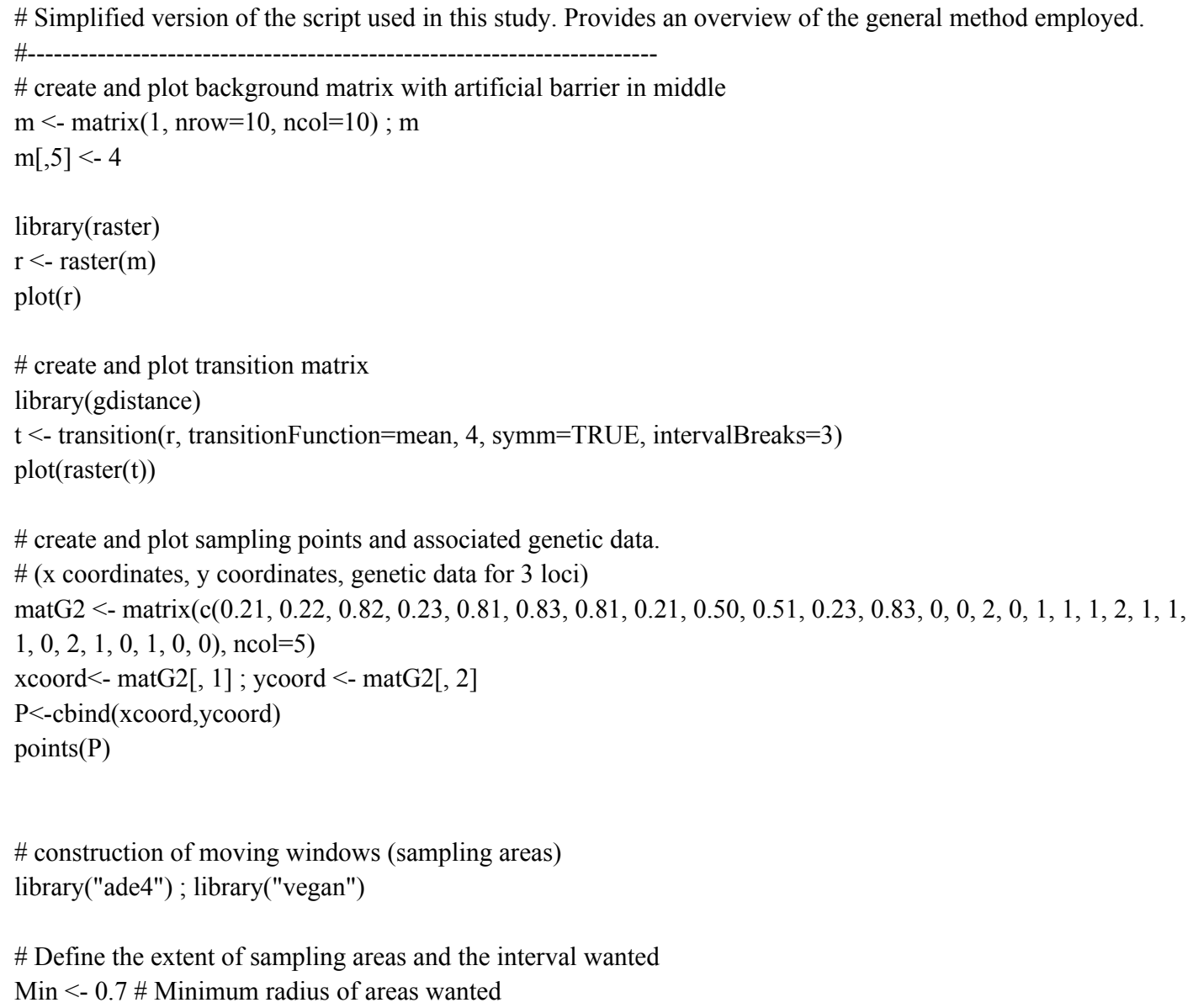


828

829

830

831

832

833

834

835

836

837

838

839

840

841

842

843

844

845

846

847

848

849

850

851

852

853

854

855

856

857

858

859

860

861

862

863

864

865

866

867

868

869

870

871

872

873

874

875

876

877

878

879

880

881
Max <- 0.9 \# Maximum radius of areas wanted

Step $<-0.1$ \# interval wanted

\# Loops to test correlations in sampling area on multiple scales and in multiple locations resultsfinal $<$ - cbind $(1,1,1,1,1)$

colnames(resultsfinal) <- c("xcoord","Ycoord", "Radius", "MantelR", "Pval")

for(Radius in seq(Min, Max, by $=$ Step) $)\{$

results $=$ NULL

for(i in 1:length(xcoord $))\{$

Xcircle $<-($ xcoord $[i]+$ Radius* $\cos (\operatorname{seq}(0,2 *$ pi,length.out $=100)))$

Ycircle $<-($ ycoord $[i]+$ Radius* $\sin (\operatorname{seq}(0,2 *$ pi,length.out $=100)))$

polygon(Xcircle, Ycircle)

\# extract individual data in each sampling are constructed

expr $<$ - point.in.polygon(xcoord,ycoord,Xcircle,Ycircle)

$\operatorname{xcoord}[\operatorname{expr}==1]$

ycoord[expr $==1]$

coordPoly $<$ - cbind $(\mathrm{xcoord}[\operatorname{expr}==1], \mathrm{ycoord}[\operatorname{expr}==1])$

\# sort data and compute matrix of basic pairwise euclidian distances (not used further in this example)

CoordOrder<- coordPoly[order(coordPoly[,1],decreasing=FALSE), ]

locOrder $<$-data.frame(CoordOrder)

DisGeoEucl<-dist(locOrder, method = "euclidean", diag = TRUE, upper = TRUE)

\# compute corresponding matrix of genetic distances

listcoord $=(1: 6)[$ expr $==1]$

Genet $=$ NULL \#\# fichier vide pour collage des données

for(h in listcoord $)\{$

$\operatorname{tmp}<-\operatorname{matG} 2[(\operatorname{matG} 2[, 1]==x \operatorname{coord}[\mathrm{h}]) \operatorname{and}(\operatorname{matG} 2[, 2]==$ ycoord $[\mathrm{h}])$,

Genet $=$ rbind $($ Genet, tmp $)$

\}

GenetOrder $<-$ Genet[order(Genet[,1],decreasing=FALSE), ]

GenetOrderSanscoord <- GenetOrder[,-c(1,2)]

MatdistGenet $<-$ vegdist(GenetOrderSanscoord, method="bray", binary=FALSE, diag=FALSE, upper=TRUE, na.rm = TRUE)

MatdistGenet $<$ - as.dist(MatdistGenet)

\# Compute matrix landscape "resistance" distances based on raster

spatiallocX $<-$ locOrder[,1] \#\# extraction des colonnes pour repasser en spatial

spatiallocY $<-$ locOrder[,2]

SpaLoc $<$ - SpatialPoints(cbind(spatiallocX, spatiallocY))

Resdis $<-$ commuteDistance(t, SpaLoc)

Resdis $<$-as.dist(Resdis, diag $=$ TRUE, upper=TRUE)

\# simple mantels test between genetic and landscape "resistance" distances

MantelpRes <- mantel.rtest(MatdistGenet, Resdis, nrepet $=99$ )

results $<$ - rbind (results, cbind (xcoord [i], ycoord [i],Radius, MantelpRes[2], MantelpRes[4]))

\}

resultsfinal $<$ - rbind(resultsfinal,results)

\}

\# display result file with for each individual: $\mathrm{x}$ and $\mathrm{y}$ coordinates, radius of sampling area, mantel output and associated $\mathrm{p}$-value Resultsfinal 
882

883

884

885

886

887

888

889

890

891

892

893

894

895

896

897

898

899

900

901

902

903

904

905

906

907

908

909

910

911

912

913

914

915

916

917

918

919

920

921

922

923 Figure S2: Number of individuals in sampling areas across the spatial scale (Mean: black; +/- SD: gray).

924 Figure S3: Evolution of DeltaK for an increasing value of K (2 -20).

\section{Supplementary Material}

Table S1: Sampling details for the 132 demes. (Long. and Lat. refer to the geographic coordinates of the sampling sites; $N$. is the number of individuals of demes; A. mean allelic richness; AR. corrected allelic richness, accounting for variation in deme size; $F_{i s} . F_{i s}$ estimate of deme, computed without Mon01 and Mon 27)

Table S2: Details of primer sequence and genotyping.

\section{Protocol}

Multiplexed PCR were performed in a $10 \mu \mathrm{L}$ reaction volume using $25 \mathrm{ng}$ of genomic DNA, $0.4 \mathrm{U}$ of DreamTaq DNA Polymerase (Thermo Scientific ${ }^{\circledR}$ ), $0.75 \mu \mathrm{L}$ Dream Taq Green Buffer (including $20 \mathrm{mM}$ $\mathrm{MgCl}$, Thermo Scientific $\left.{ }^{\circledR}\right), 1 \mu \mathrm{M}$ Betaine, $0.24 \mu \mathrm{L}$ dNTP $(10 \mu \mathrm{M})$ and deionized H2O. PCR amplifications were run on a Veriti ${ }^{\circledR} 96$ well fast thermal cycler (Applied Biosystems ${ }^{\circledR}$ ) using the following settings: a first denaturation step at $95^{\circ} \mathrm{C}$ for $10 \mathrm{~min} ; 40$ cycles of denaturation $\left(30 \mathrm{~s}\right.$ at $\left.95^{\circ} \mathrm{C}\right)$, hybridization $\left(30 \mathrm{~s}\right.$ at $\left.55^{\circ} \mathrm{C}\right)$ and elongation $\left(1 \mathrm{~min}\right.$ at $\left.72^{\circ} \mathrm{C}\right)$, and a final elongation step at $72^{\circ} \mathrm{C}$ for $10 \mathrm{~min}$. One $\mu \mathrm{L}$ of PCR products was denatured in a mix of $10 \mu \mathrm{L}$ of formamide and $0.3 \mu \mathrm{L}$ of $600 \mathrm{Liz}$ marker before being run on an ABI PRISM 3500 sequencer (Life Technologies ${ }^{\circledR}$ ). Genotypes were read using GENEMAPPER V 4.1 software (Applied Biosystems ${ }^{\circledR}$ ).

Table S3: Sampling locations and microsatellite genotypes.

Figure S1: Distribution of sampling sites in the Iberian Peninsula. Black dots refer to populations of size $>19$ individuals. The green background refers to elevation (from pale to dark green: low to high elevation). 
Figure 1

Genetic clustering of 992 individuals of Monochamus galloprovincialis sampled at 132 locations

A: Assignment of individuals to clusters based on a STRUCTURE analysis for $K=2$. B:

Assignment of demes to clusters for $k=2$, displayed in geographic context (Iberian Peninsula, the size of the pies refers to the size of the demes). C: PCA of individuals on first and second axes, colors and ellipses refer to demes.

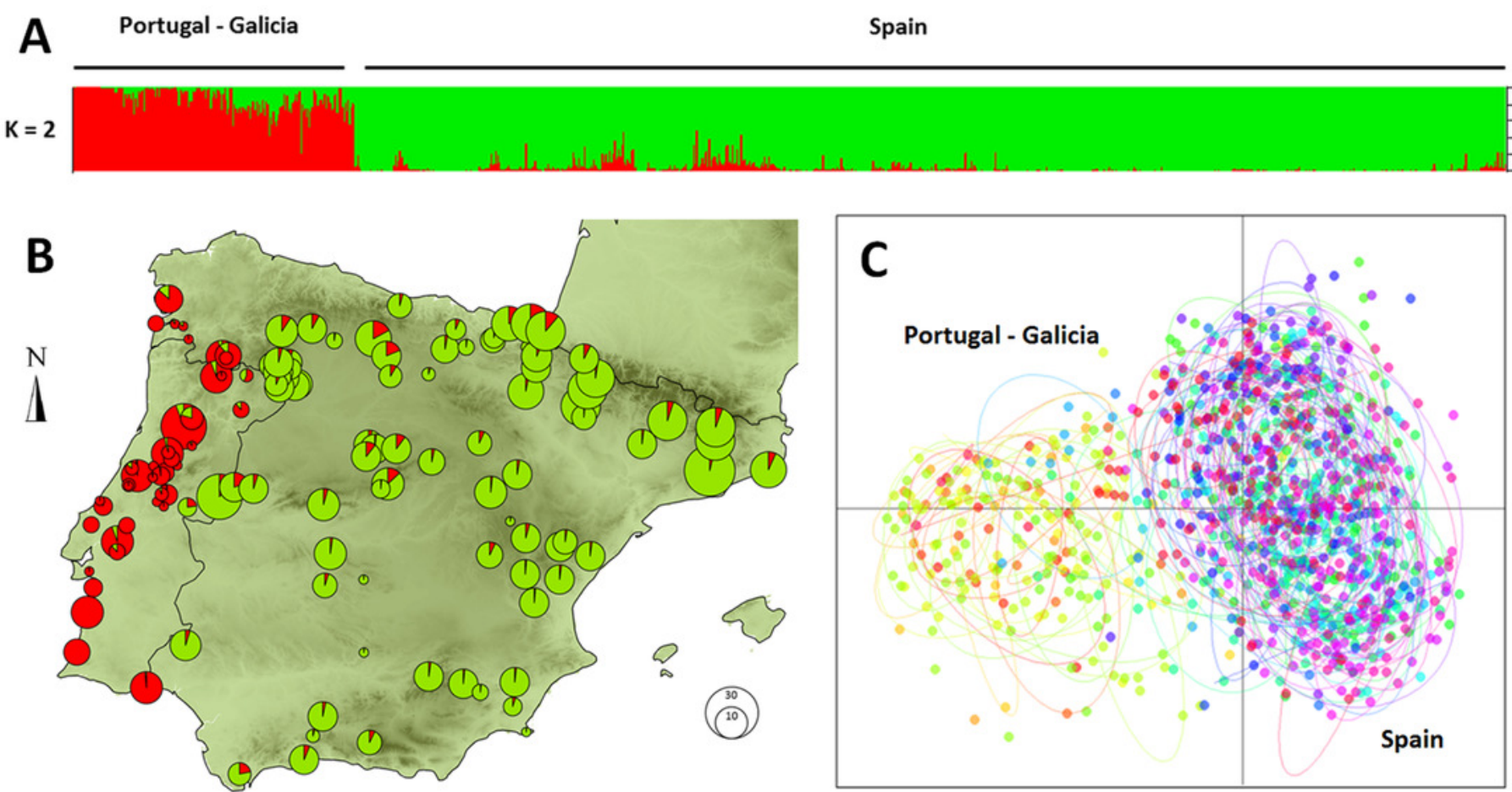


Figure 2

Empirical semi-variogram of genotypes of Monochamus galloprovincialis.

The variogram was fitted with an exponential model to highlight the first plateau. Data points are shown with a spatial lag distance of $50 \mathrm{~km}$.

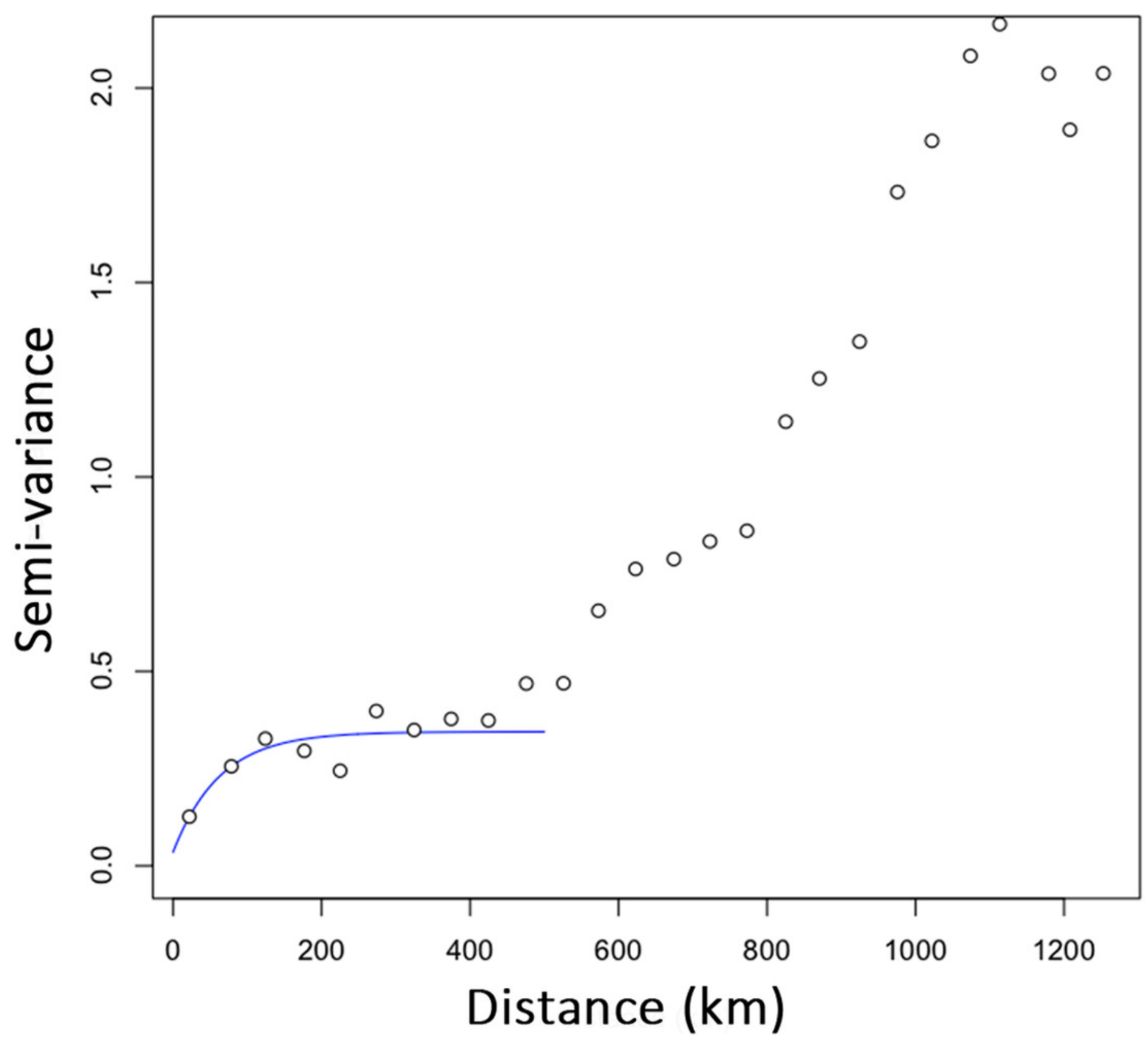


Figure 3

Percentage of areas with supported IBR hypotheses for Mantel tests (A) and mean partial Mantel $r(B)$ of areas with support for the IBR hypotheses $(p<0.05)$ with increasing scales (whole dataset).

E: Elevation, $T$ : Mean minimum temperatures, $\operatorname{Pr}$ and $P C$ : pine densities as a resistant feature and as a corridor respectively, IBD: Isolation by distance.
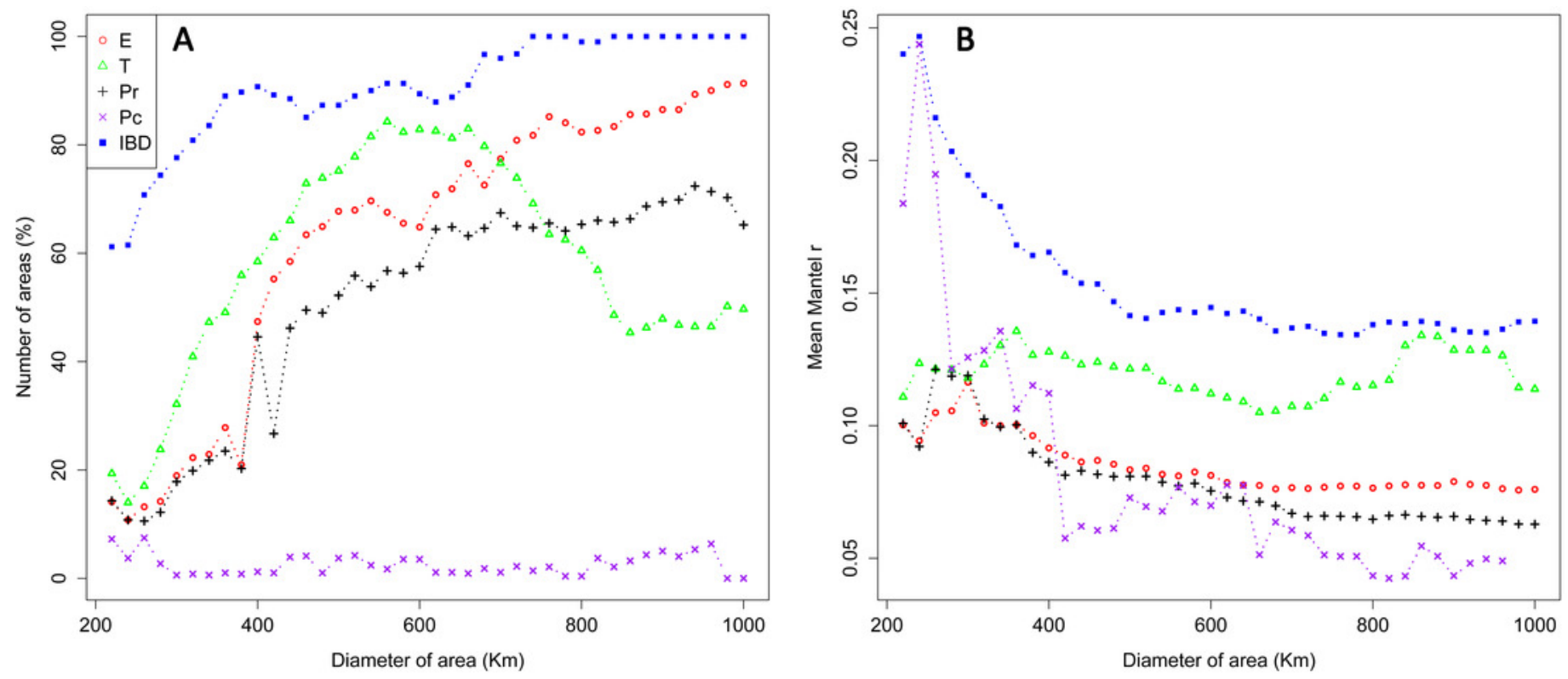


\section{Figure 4}

Distribution of supported IBR hypotheses through Mantel tests for the environmental features tested

(IBD: Euclidian distances; T: mean minimum temperatures; E: elevation; Pr: high pine densities as barriers; Pc: high pine densities as corridors). Gray maps (A) refer to the distribution of environmental features associated with resistance models (From white to black: low to high resistance values). Colored maps refer to interpolations of supported IBR hypotheses on the whole dataset (B) and within the western Iberian cluster only (C). From blue to red: low to high frequency of study areas with supported resistance models. 

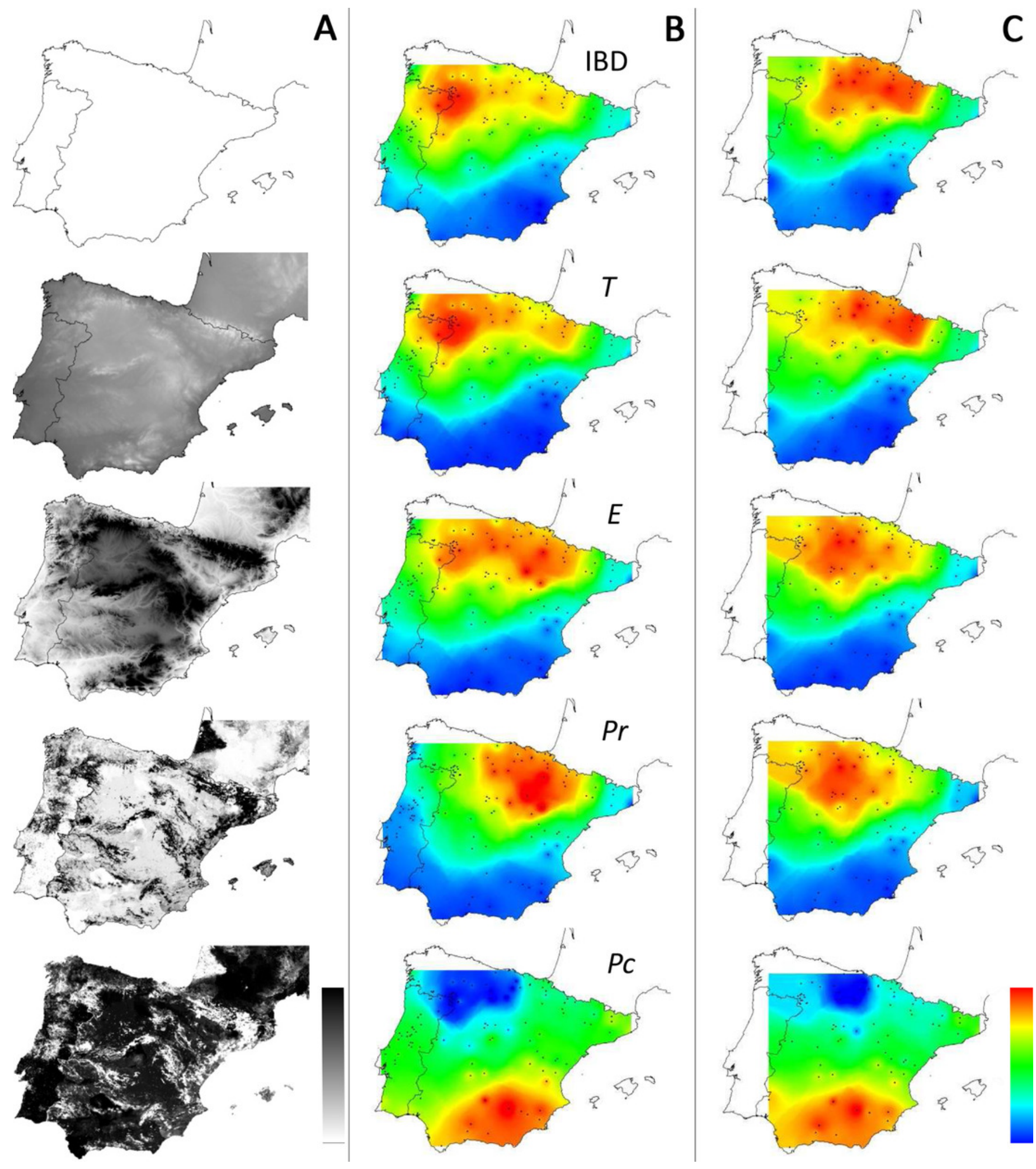
Figure 5

Spatial heterogeneity (mean standard deviation, SD) of environmental features in areas with supported and non-supported resistance hypotheses through Mantel tests with increasing scales.

Mean SD: mean standard deviation. T: mean minimum temperatures (A); E: elevation (B); Pr: high pine densities as barriers (C); PC: high pine densities as corridors (D). sig: significant, non-sig: non-significant.
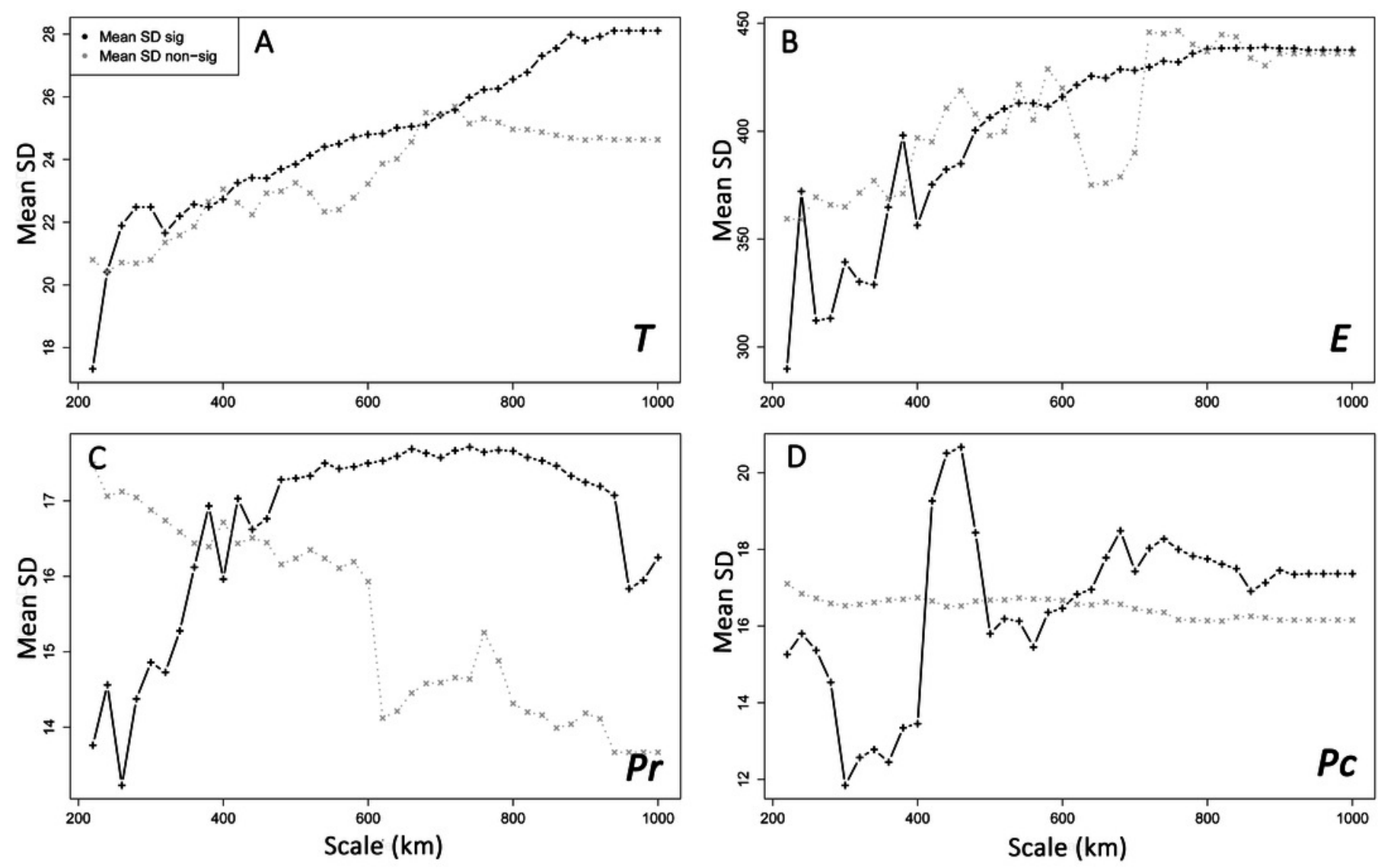


\section{Table $\mathbf{1}$ (on next page)}

Commonality coefficients of both unique and common effects for the three sampling areas with the highest variance explained.

Code pop: population code for the center of the sampling area. Scale: diameter of sampling area $(\mathrm{km}) . \mathrm{N}$ : number of individuals in sampling area. Coef.: percentage of variance explained by environmental features (IBR hypotheses). \% Total: percentage of the contribution of environmental features to the total variance explained. Environmental features and their associated Isolation By Resistance (IBR) hypothesis: $E$ : elevation model (high elevations $=$ resistance to dispersal). $P$ c: Pine density model (high pine density $=$ corridors to dispersal. Pr: reversed pine density model (high pine density $=$ resistance to dispersal). $T$ : temperature model (low minimum annual temperatures $=$ resistance to dispersal). 


\begin{tabular}{|c|c|c|c|c|c|c|c|}
\hline \multicolumn{2}{|c|}{$\begin{array}{l}\text { Code pop } \\
\text { Scale } \\
\mathbf{N}\end{array}$} & \multicolumn{2}{|c|}{$\begin{array}{l}85 \\
620 \\
225\end{array}$} & \multicolumn{2}{|c|}{$\begin{array}{l}130 \\
540 \\
254\end{array}$} & \multicolumn{2}{|c|}{$\begin{array}{l}131 \\
520 \\
244\end{array}$} \\
\hline \multirow{5}{*}{$\begin{array}{l}\frac{1}{8} \\
\frac{0}{0} \\
\vdots \\
\frac{1}{n} \\
\end{array}$} & IBR hypotheses & Coef. & \% Total & Coef. & $\%$ Total & Coef. & \% Total \\
\hline & $E$ & 0,008 & 3,408 & 0,001 & 0,351 & 0,002 & 0,807 \\
\hline & $T$ & 0,050 & 20,775 & 0,070 & 32,651 & 0,059 & 28,108 \\
\hline & PC & 0,004 & 1,806 & 0,008 & 3,678 & 0,008 & 3,811 \\
\hline & Pr & 0,085 & 35,235 & 0,047 & 21,817 & 0,046 & 22,214 \\
\hline \multirow{6}{*}{$\begin{array}{l}\frac{d}{0} \\
\frac{0}{0} \\
\frac{1}{0} \\
\vdots \\
\text { v }\end{array}$} & $E, T$ & 0,136 & 56,426 & 0,117 & 54,314 & 0,115 & 54,953 \\
\hline & $E, P C$ & $-0,003$ & $-1,255$ & $-0,001$ & $-0,243$ & $-0,001$ & $-0,430$ \\
\hline & $T, P C$ & 0,001 & 0,426 & 0,007 & 3,236 & 0,010 & 4,893 \\
\hline & $E, P r$ & $-0,002$ & $-0,897$ & 0,031 & 14,375 & 0,020 & 9,721 \\
\hline & $T, P r$ & $-0,013$ & $-5,398$ & 0,018 & 8,406 & 0,014 & 6,540 \\
\hline & $P c, P r$ & 0,024 & 10,049 & 0,008 & 3,579 & 0,011 & 5,333 \\
\hline \multirow{6}{*}{$\begin{array}{l}\frac{d}{0} \\
\frac{0}{0} \\
\frac{1}{0} \\
\frac{m}{2}\end{array}$} & $E, T, P c$ & 0,014 & 5,724 & $-0,005$ & $-2,311$ & $-0,001$ & $-0,474$ \\
\hline & $E, T, P r$ & $-0,023$ & $-9,712$ & $-0,069$ & $-32,007$ & $-0,047$ & $-22,356$ \\
\hline & $E, P c, P r$ & 0,003 & 1,313 & 0,026 & 12,118 & 0,030 & 14,509 \\
\hline & $T, P c, P r$ & $-0,009$ & $-3,795$ & 0,006 & 2,961 & 0,010 & 4,950 \\
\hline & $E, T, P c, P r$ & $-0,034$ & $-14,106$ & $-0,049$ & $-22,926$ & $-0,068$ & $-32,581$ \\
\hline & Sum & 0,240 & 100 & 0,216 & 100 & 0,209 & 100 \\
\hline
\end{tabular}

